\title{
Mating patterns, pollen dispersal, and the ecological maternal neighbourhood in a Prunus mahaleb L. population
}

\author{
C. GARCÍA, ${ }^{*+J}$ J. M. ARROYO,${ }^{*}+\mathrm{J}$. A. GODOY*† and P. JORDANO* \\ *Integrative Ecology Group and +Laboratory of Molecular Ecology, Estación Biológica de Doñana, CSIC, Pabellón del Perú, Avda. \\ María Luisa, s/n, E-41013 Sevilla, Spain
}

\begin{abstract}
Gender polymorphism, plant-animal interactions, and environmental heterogeneity are the three important sources of variation in mating system and pollen dispersal patterns. We used progeny arrays and paternity analysis to assess the effects of gender type and density level on variation in mating patterns within a highly isolated population of Prunus mahaleb, a gynodioecious species. All the adult trees in the population were sampled and located. The direct estimate of long-distance insect-mediated pollination events was low $(<10 \%)$. Gender expression deeply influenced the mating system, decreasing the outcrossing rates $\left(t_{m}\right)$ and the pollen pool diversity in hermaphrodite trees. Long intermate distances $(>250 \mathrm{~m})$ were significantly more frequent among female mother trees. Variation in local tree density also affected pollen pool diversity and intermate distance, with a higher effective number of fathers $\left(k_{e}\right)$ and longer intermate distances for female trees in low-density patches. A canonical correlation analysis showed significant correlations between mating variables and the maternal ecological neighbourhood. Only the first canonical variable was significant and explained $78 \%$ of variation. Outcrossing rates tended to decrease, and the relatedness among the fathers tended to increase, when mother trees grew in dense patches with high cover of other woody species and taller vegetation away from the pine forest edge. We highlight the relevance of considering maternal ecological neighbourhood effects on mating system and gene flow studies as maternal trees act simultaneously as receptors of pollen and as sources of the seeds to be dispersed.
\end{abstract}

Keywords: canonical correlation analysis, environmental heterogeneity, mating system, paternity analysis, pollen dispersal

Received 16 October 2004; revision received 26 January 2005; accepted 11 February 2005

\section{Introduction}

A long-lasting question in plant reproductive biology relates to mechanisms influencing the evolution of mixed-mating systems and their contribution to genetic diversity within a population (Charlesworth \& Charlesworth 1978). Accurate fine-scale measures of the mating system can be obtained using molecular markers, and most of the previous studies have estimated outcrossing rates as population averages (Ritland 2002). A wide range of variation has been found, however, at the individual plant level in Cavanillesia platanifolia (Murawski \& Hamrick 1992), where outcrossing rate estimates varied between 0 and 0.95 depending on the

Correspondence: Cristina García, Fax: + 3495 4621125. E-mail: crisgarcia@ebd.csic.es density of flowering trees around the maternal tree. Thus, the mating system is subject to maternal ecological correlates that differ among individuals within a population, especially in heterogeneous landscapes (Schnabel \& Hamrick 1995; O'Connell et al. 2004). An additional step is needed to elucidate the structure and strength of the interaction between mating and ecological variables within a population. This goal needs to be approached under a spatial-explicit framework incorporating the environmental heterogeneity of the natural populations, i.e. extending the approach of Sork et al. (1999) for the study of pollen flow from the landscape level to the local (population) scale.

We assessed variation in both mating system and maternal ecological neighbourhood in order to identify the maternal correlates shaping mating and pollen dispersal patterns in a population of Prunus mahaleb L., a gynodioecious 
species (i.e. having hermaphrodite and functionally female trees). We used microsatellite markers and a mixed-mating model developed by Ritland (1989) to estimate outcrossing rates $\left(t_{m}\right)$. For studies aiming to test the impact of one or more male-specific features on relative reproductive success, a fractional assignment procedure is recommended (Devlin et al. 1988). Moreover, male reproductive success or ongoing pollen flow studies are usually carried out in large populations where pollen flow is extensive and the genotyping of all potential pollen donors is not feasible (Smouse \& Sork 2004). In such cases, mating models that incorporate prior information influencing male relative success are fitted to multilocus genotypes from mother-offspring arrays (Burczyk et al. 1996). However, because we deal with a highly isolated population where all trees have been sampled, and our molecular markers reach a high exclusion probability (EP), we apply a direct approach based on paternity analysis and maximum-likelihood methods to assign paternity to progeny arrays (Meagher 1986; Devlin et al. 1988; Adams et al. 1992). A low percentage of pollen immigration is expected because of a marked physical isolation and of non-overlapping phenology with surrounding populations.

The maternal reproductive trees in a population (i.e. functional female trees) are key elements in the demography and natural regeneration cycles. They act as pollen targets during pollination, provide the environment for progeny growth, and become sources for seed dispersal. Therefore, understanding variation in female success as pollen receptors and as sources of dispersing seeds is a central issue in gene flow studies (Ennos 2001). There are three potential factors determining mating and pollen dispersal traits within the P. mahaleb study population: (i) the gender type, as female and hermaphrodite (and autocompatible) trees coexist; (ii) pollinator foraging behaviour, as it is an insect-pollinated species; and (iii) the maternal ecological neighbourhood in a highly heterogeneous landscape.

Selfing has a pervasive influence because of decreasing pollen pool diversity (number of siring trees, their contribution, and the genetic relatedness among them) and intermate distance for the progeny of hermaphrodite trees. Moreover, female and hermaphrodite trees can differ in reproductive resource allocation or floral biology (Gibson \& Diggle 1997) and pollinators are sensitive to these variations (Murawski 1987). Jordano (1993) recorded higher visitation rates in female trees and significant differences between gender types in the pollinator assemblages in the study population resulting from significant differences in the nectar volume secreted per flower and per day. Consequently, the differential activity of the pollinators on female and hermaphrodite flowers would shape the mating and pollen dispersal patterns beyond the foreseeable effects of selfing. On the other hand, the spatial arrangement of the conspecific trees determines pollen dispersal distance, as shown by Handel (1983) who found restricted pollen dispersal when trees were clumped instead of following a regular arrangement. Additionally, the maternal ecological neighbourhood differs individually in ecological characteristics such as vegetation structure, which might increase or decrease mating variation depending on the ecological requirements of the pollinator community (Godt \& Hamrick 1993).

According to Van Treuren et al. (1993), outcrossing rates among individuals of animal-pollinated species vary as a result of plant density and gender polymorphism, mainly because of related changes in flower production. Nonetheless, the effects of tree density and gender type on pollen pool diversity still remain unclear. These two factors would be expected to modulate pollen pool diversity and, presumably, intermate distance. Previous analyses show that no single factor explains variation in mating success among male (Smouse et al. 1999) or female trees (Schnabel \& Hamrick 1995). Currently, multivariate techniques are useful tools to quantify the relative contribution of multiple individual characteristics acting simultaneously to shape variation in mating patterns on a fine scale (Angers et al. 1999; Gram \& Sork 2001). Here, we used canonical correlation analysis (CCA) to relate mating system variation among mother trees (outcrossing rates, number and diversity of distinct fathers, and distance to the pollen sources) to a set of variables defining tree characteristics and the ecological maternal neighbourhood.

In this study, we analyse two major factors influencing mating system and pollen dispersal patterns: gender expression and density of conspecifics. Additionally, the maternal and ecological correlates that determine mating variation within the population are explored. Specifically, the aims are (i) to estimate the proportion of pollen immigration; (ii) test the effect of gender type and density level on outcrossing rates; (iii) evaluate the effects of these two factors on pollen pool diversity in terms of number of fathers $(k)$, effective number of fathers $\left(k_{e}\right)$, and relatedness among the fathers siring a progeny $(r)$; (iv) assess the effect of gender type and density level on intermate distances; and (v) study the multivariate relationship between mating system variation and the characteristics of the mother trees and their ecological neighbourhood in heterogeneous landscapes.

\section{Materials and methods}

\section{Species characteristics and study site}

The species under study is Prunus mahaleb L., a rosaceous treelet that in southeastern Spanish populations is gynodioecious, with some individuals producing hermaphrodite flowers and others with androsterile flowers which behave as functional females (Jordano 1993). In the southern Iberian Peninsula, this species flowers between mid-May and 
mid-June at high elevations (over $1300 \mathrm{~m}$ ) and its pollen vectors include insects, mainly bees (Hymenoptera: Andrenidae, Apidae) and flies (Diptera: Calliphoridae, Syrphidae) (Jordano 1993). Prunus mahaleb produces fleshy fruits (drupaceous) with one seed per fruit. In late July, fleshy fruits are produced and consumed by frugivorous animals that disperse the seeds until late August or early September P. mahaleb is widely distributed in central, southern, and eastern Europe and west-central Asia (Webb 1968). In the southeastern Iberian Peninsula, it thrives both on deep soil and exposed rocky slopes.

The study population is located in Nava de las Correhuelas (Parque Natural de Sierra de Cazorla, Segura y las

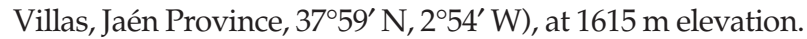
The site is dominated by grasslands with scattered patches of deciduous vegetation, gravelly soil or rock outcrops covered with shrubs or small isolated trees. The rocky slopes are dominated by open pine forest (Pinus nigra ssp. salzmannii) (Valle et al. 1989). Our population consists of 104 hermaphrodite and 92 female trees, with a scattered and patchy distribution as shown in Fig. 1. Populations of $P$. mahaleb are typically found in this region as small, isolated patches of trees, frequently with $<100$ trees. The nearest $P$. mahaleb population is located at $1.5 \mathrm{~km}$.

\section{Sampling design}

The study population was previously genotyped and mapped by Godoy \& Jordano (2001) with a few trees added to this previous sample. These trees grow in a small patch $300 \mathrm{~m}$ north of Nava de las Correhuelas and have been included in the population sample. This represents a thorough sample of the whole population and we are confident that it includes all the reproductive trees (Fig. 1).

The random selection consisted of 20 mother trees stratified by gender type and local density of adult conspecifics. Local density levels were defined for each tree based on the number of conspecifics within a $15-\mathrm{m}$ radius. This threshold value was determined from an analysis of the nearest neighbour distances. Trees in high density had at least four conspecifics within this distance and low density trees had one to two conspecifics. Finally, there were four groups with $N=$ 5 mother trees per group in four combinations of gender type $\times$ density: female low density (FL); female high density (FH); hermaphrodite low density (HL); and hermaphrodite high density $(\mathrm{HH})$. Ten fruits were randomly collected from each mother tree at the start of the ripening period with 50 fruits analysed per group and a total of 200 seeds sampled.

Six variables characterizing the maternal tree and its ecological neighbourhood were measured: area of the vertical projection of the canopy (CNPY); mean height of woody shrubs beneath the canopy (UCHGT); the number of species beneath the canopy (UCSP); the percentage of woody cover beneath the canopy (UCWC); under canopy rocky cover

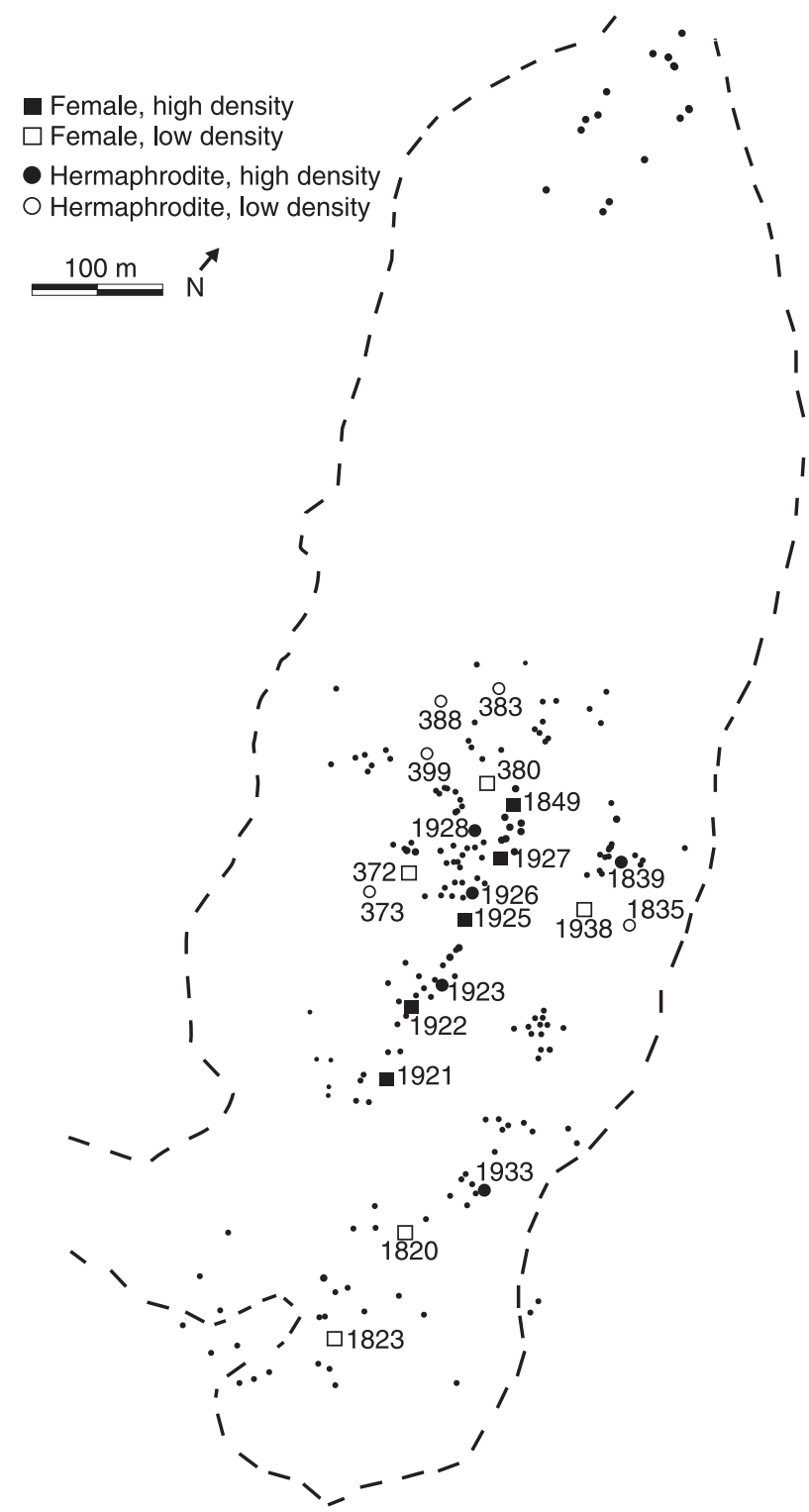

Fig. 1 Spatial distribution of all adult trees $(N=196)$ in the study site. Small dots indicate the locations of all the reproductive trees. The mother trees included in this study are indicated with squares (female mother trees) or circles (hermaphrodite mother trees). Density situations are indicated by solid (high density) and open (low density) symbols. Numbers are the identifier for each tree. The dashed lines indicate the approximate location of the pine forest edge.

(UCOVR); and distance to the pine forest edge (DFOREST, see Fig. 1). All variables were measured at four regularly located points in the four compass directions from the main trunk of the tree (see Jordano \& Schupp 2000).

\section{Molecular typing}

Each harvested seed was separated from the pulp and the embryo carefully extracted from the seed endocarp and 
seed coat. DNA was extracted from all embryos using a SIGMA GenElute Plant Genomics DNA kit, with 5-10 $\mu \mathrm{L}$ used as a template for polymerase chain reaction (PCR) in a final volume of $20 \mu \mathrm{L}$ (see Godoy \& Jordano 2001 for protocol details). All embryos were genotyped using 10 microsatellite markers previously used to type the adult trees (Godoy \& Jordano 2001). Amplified fragments were analysed using an ABI 310 Capillary Electrophoresis system (Applied Biosystem) and fragment sizes were assessed using GENESCAN analysis version 3.1.2 and GENOTYPER version 2.5 software using TAMRA 350 (Applied Biosystem) as a size standard. The multilocus genotypes of all trees differed in at least one allele per locus. Each marker presented between two and 21 alleles with an estimated mean number of 7.6 alleles per locus and a paternity exclusion probability (i.e. the probability to exclude a randomly chosen nonfather based on allele frequencies) of 0.996 . Three embryos were excluded from the analysis because of several mismatches with the mother tree. The incidence of null alleles was discarded, as mismatching occurred at several heterozygous loci. Moreover, in previous work by Godoy \& Jordano (2001) where progeny from diallelic crosses of known sires and dams were compared with parental genotypes, no evidence was found for the occurrence of null alleles. Allele scoring was carefully checked several times by different persons in order to minimize the scoring error rate.

\section{Data analysis}

Paternity analysis. Paternity analyses (the assignment of a putative father to a genetically known mother-offspring pair) were performed using CERvUs version 2.0 (Marshall et al. 1998), a software program based on maximum-likelihood methods (Meagher 1986). In addition, 10000 simulations were run with the same sample size and allele frequency as the study population to assign confidence levels to paternity analysis ( $95 \%$ or $80 \%$ by default). CERVus uses five parameters set by the user: (i) the minimum number of matching loci (eight loci); (ii) error rate $(0.1 \%)$; (iii) number of candidate parents $(104$, including all the hermaphrodite trees within the population); (iv) proportion of candidate parents sampled ( 0.95 as a conservative estimate); and (v) proportion of loci typed (0.99). In this work, a relaxed confidence level of $80 \%$ was used, as we are less interested in identifying particular mates than in drawing a general picture of pollen movement within the population. Following the criteria proposed by Slate et al. (2000), the most likely father assigned at an $80 \%$ confidence interval was accepted when its LOD score was $\geq 3$ and rejected when $\leq-3$. When the LOD score was between 3 and -3 , no most likely father was assigned. In spite of the high exclusion probability reached, a fraction of the offspring assigned to the most likely father may be erroneously assigned to a putative father within the population, whereas the true father is outside the population.
This defines cryptic gene flow (CGF) (Devlin \& Ellstrand 1990) and was estimated here using FAMOz software (Gerber et al. 2003). A simulated population was built with the following parameters: simulated offspring $(N=200)$, error rate $(0.1 \%)$, number of mothers $(N=20)$, and number of contributing fathers $(N=104)$.

Mating system and pollen dispersal distances. Outcrossing rates $\left(t_{m}\right)$ were estimated using MLTR version 3.0 software based on the method of moments, a more accurate procedure than maximum likelihood when dealing with small progeny size (Ritland 2002). Both single locus and multilocus outcrossing rates were obtained ( $t_{s}$ and $t_{m^{\prime}}$ respectively), but only the $t_{m}$ data are reported because they yielded similar values. The result of paternity analysis using CERVUS version 2.0 was then used to obtain the minimum number of fathers siring each mother tree $(k)$. The effective number of fathers $\left(k_{e}\right)$ was estimated according to Nielsen et al. (2003), who provided an unbiased estimator of the effective number of fathers for small sample sizes, $k_{e}$ :

$$
k_{e} \approx \frac{(n-1)^{2}}{\sum_{i=1}^{k_{0}} \hat{p}_{i}^{2}(n+1)(n-2)+3-n}
$$

with an approximate variance, $V\left[k_{e}\right]$

$V\left[k_{e}\right]=\frac{2 k^{2}(k-1)(n-2)^{2}(n-1) n(n+1)^{2}}{(2 k+(n-2)(n+1))^{4}}$

where $n$ is the number of embryos analysed, $k$ is the number of distinct fathers, and $p_{i}^{2}$ is the frequency of each different father.

Using SPAGEDI (Hardy \& Vekemans 2002), an estimation of the relatedness was also made ( $r$, Queller \& Goodnight 1989) among fathers siring each mother tree, defining 20 groups (one per mother tree), each containing the fathers siring each progeny. Pairwise comparisons were restricted to within groups regardless of the spatial location of the trees, and using $N=10000$ permutations.

Significant differences among groups were tested using a two-way general linear model (GLM) with Poissondistributed errors and a log link function for $k$ and $k_{e}$; otherwise, normal errors and an identity link were used, as in usual analysis of variance (ANOVA) (Venables \& Ripley 2002). The posthoc differences were checked with a TukeyKramer HSD test (Zar 1999). Two separate sets of analyses were performed, one involving the whole progeny sample of the hermaphrodite trees and a second one excluding the selfed progeny. We report the estimates of mating parameters for both sets of samples, although only the complete set (including the selfed progeny) reflects the real mating pattern in nature. All analyses were carried out using the $\mathrm{R}$ package (R Development Core Team 2003). 
Measurements consisted of the distance between the mother and the putative father (intermate distance) when one most likely father was assigned, given the geographical coordinates $(x, y)$ in a GIS-referenced map using ARCVIEW version 3.0a software (Mitchell 1999). In addition, the distances between each mother tree and all hermaphrodite trees (potential intermate distance) were also measured to determine if the observed intermate distance $(d)$ was influenced by the spatial arrangement of the adult trees. A comparison was made of the skewness $\left(g_{1}\right)$ and the kurtosis $\left(g_{2}\right)$ of the frequency distributions of both distances. Within each group of gender and local density combination, the observed and potential frequency distribution distances were compared using a Wilcoxon matched pair test (Zar 1999). The effect of gender type and density level on intermate distance was tested using a GLM analysis (R Development Core Team 2003). All analyses were carried out with both inclusion and omission of the selfed progeny of the hermaphrodite trees.

Canonical correlation analysis. Relationships between mating measurements and ecological variables were examined by means of CCA. The mating pattern for each tree was defined by mating variables estimated from the progeny genotyping: median intermate distance $(d)$, minimum number of distinct fathers $(k)$, effective number of fathers $\left(k_{e}\right)$, multilocus estimate of the outcrossing rate $\left(t_{m}\right.$, Ritland 2002), and relatedness among fathers siring the sampled progeny $(r$, Queller \& Goodnight 1989). The ecological setting for each tree was defined by the six environmental variables previously described.

The CCA aims at generating composite variables (canonical variables) that maximize correlations among the sets of mating and ecological variables. These can be envisioned as mating and ecological vectors (Angers et al. 1999; Gram \& Sork 2001) that define a gradient of variation among trees in a mating system and in characteristics of the growing site. Each original variable has a correlation with the new canonical variables, which define a canonical structure that can be used to interpret them. The canonical correlation squared $\left(R^{2}\right)$ is the percentage of variance in the dependent set explained by the independent set of variables along a given dimension. In order to asses whether this relationship is significant, the CCA uses a Wilk's lambda test (Everitt \& Dunn 1991). We used PROC CANCORR (SAS Institute 1998) to carry out the canonical correlation analysis.

\section{Results}

\section{Paternity analysis and pollen immigration}

A single most likely father was assigned to 160 embryos $(81.21 \%)$, all of them with a LOD score of $\geq 3$. Several compatible fathers, but no most likely father was found for 24 embryos (12.29\%), all of them with a LOD score between 3 and -3 . For 13 embryos (6.5\%), the most likely father assigned was rejected as it had a LOD score value of $\leq-3$. Every time a most likely father was rejected, all candidate fathers had more than three mismatches with the embryo. When the estimated CGF is added to the estimate of apparent gene flow, the percentage of pollen immigration is $9.5 \%$. Given the high exclusion probability $(\mathrm{EP}=0.996)$ and exhaustive sampling of the adult trees, it can be assumed that this percentage represents a robust estimate of the percentage of pollen immigration in our population.

\section{Gender type and density level effects on mating system}

Results shown in Table 1 confirm that all pollination events recorded in female trees were outcrossed $\left(t_{m}=1\right)$ whereas the hermaphrodite mother trees had considerably lower levels of outcrossing $\left(t_{m}=0.37-0.46\right)$, significantly different from $t_{m}=1\left(\chi^{2}=2.83\right.$, d.f. $=9$, and $\left.P<0.05\right)$. Thus, more than half of the progeny from hermaphrodite trees were selfed, with an average estimate of outcrossing of $t_{m}=0.41$ for HL

Table 1 Mean ( $\pm 1 \mathrm{SD}$ ) values for mating system and pollen dispersal variables. Mating system was characterized by $t_{m}$ (mean multilocus outcrossing rate), $k$ (number of distinct fathers), $k_{e}$ (effective number of fathers), and $r$ (relatedness among the fathers siring each progeny). We also report the mean, the first quartile $\left(Q_{25}\right)$, the third quartile $\left(Q_{75}\right)$, and the minimum $(\mathrm{min})$ and maximum (max) intermate distances recorded for each group of trees. The number of seeds sampled per group is $n$. Two series of values are reported for the hermaphrodite mother trees: those for the complete sample and those excluding the selfed progeny (indicated by ' -0 ' suffix)

\begin{tabular}{|c|c|c|c|c|c|c|c|c|}
\hline Gender type & Density & $n$ & $t_{m}^{*}$ & $k^{*}$ & $k_{e}^{*}$ & $r^{*}$ & Mean $\left(Q_{25}-Q_{75}\right)^{*}$ & Min-Max \\
\hline Female & Low & 50 & $1.01(0.02)^{a-1}$ & $7.9(1.5)^{a-1}$ & $5.7(0.4)^{\mathrm{a}}$ & $0.10(0.1)^{\mathrm{a}-1}$ & $125.2[53.1-158.3]^{\mathrm{a}-1}$ & $6.7-548.1$ \\
\hline Female & High & 48 & $1.01(0.04)^{a-1}$ & $7.2(1.4)^{a-1}$ & $4.1(0.4)^{\mathrm{b}}$ & $0.31(0.11) \mathrm{a}, \mathrm{b}-1,2$ & $72.0[17.7-76.8]^{\mathrm{b}-2}$ & $1.6-362.7$ \\
\hline Hermaphrodite & Low & 44 & $0.41(0.2)^{\mathrm{b}}$ & $3.9(1.8)^{b}$ & $2.6(0.4)^{b, c}$ & $0.51(0.1)^{\mathrm{b}}$ & $91.4[0.0-29.5]^{\mathrm{b}}$ & $0.0-252.9$ \\
\hline Hermaphrodite & High & 44 & $0.49(0.3)^{b}$ & $3.1(1.1)^{b}$ & $1.6(0.4)^{\mathrm{c}}$ & $0.59(0.2)^{b}$ & $75.1[0.0-123.3]^{\mathrm{b}}$ & $0.0-278.7$ \\
\hline Hermaphrodite- 0 & Low & 15 & $0.98(0.2)^{1}$ & $3.47(0.8)^{2}$ & - & $0.45(0.1)^{2}$ & $132.9[55.8-182.8]^{1,2}$ & $23.1-252.9$ \\
\hline Hermaphrodite- 0 & High & 18 & $0.99(0.1)^{1}$ & $2.1(0.6)^{2}$ & - & $0.41(0.1)^{2}$ & $116.9[55.6-138.6]^{1,2}$ & $10.7-278.7$ \\
\hline
\end{tabular}

*Superscripts with the same letter indicate nonsignificant differences for the whole sample and superscripts with the same number indicate nonsignificant differences for the restricted sample excluding the selfed progeny of hermaphrodite trees $(P<0.05$, Tukey-Kramer HSD test). $k_{e}$ was not estimated for the hermaphrodite-0 group because of insufficient progeny size. 
and $t_{m}=0.49$ for $\mathrm{HH}$. The components of the pollen pool diversity also differed among gender types. When considering full progenies, those from female mother trees had a higher number of fathers $(k)(F=23.26$, d.f. $=1,16$, and $P<0.001$ ). When excluding selfing, low values of $k$, and large variances were obtained for hermaphrodite families, indicating that self-pollen tended to dominate the pollen pool, although to a variable degree (hermaphrodite-0; Table 1). Gender type also affected the effective number of fathers $\left(k_{e}\right)$, and the female mother trees presented almost double the $k_{e}$ of hermaphrodite trees $(F=78.20$, d.f. $=1,16$, and $P<$ $0.001)$. Additionally, progeny from FL had significantly higher $k_{e}$ compared to that from $\mathrm{FH}$, indicating that a high density of conspecifics around the mother trees lowered $k_{e}$ ( $F=6.67$, d.f. $=1,8$, and $P<0.01)$. When excluding selfing, the progeny sample per tree was too small to estimate $k_{e}$ by applying the Nielsen et al. (2003) algorithm, as it is advisable to have at least 10 offspring per mother tree for this purpose. The third component of the pollen pool diversity, the relatedness among fathers siring a progeny $(r)$, also varied between gender types $(F=6.95$, d.f. $=1,16$, and $P=0.02$ ). Among outcrossed pollination events, the offspring from female mother trees were less correlated than the offspring from hermaphrodite mother trees, with the lowest mean $r$ value found in FL mother trees (Table 1). The interaction term between gender type and density level was not significant for $r(F=0.59$, d.f. $=1,16$, and $P=0.45)$.

\section{Gender type and density level effects on pollen dispersal distance}

The frequency distribution of observed intermate distances (d) had higher skewness $\left(g_{1}=2.1\right)$ and kurtosis $\left(g_{2}=5.4\right)$ than the distribution of potential intermate distances $\left(g_{1}=1.1\right.$ and $g_{2}=0.4$, respectively) (both $t>4.1, P<0.05$ ). Observed and potential intermate distances differed for all mother tree groups (Wilcoxon matched pairs test, all comparisons $Z>2$ and $P<0.05$ ); the median observed intermate distance was always lower than the median potential distances. Gender type and density level had significant effects on $d$ when including selfed crosses $(F=15.81$, d.f. $=1,99$, and $P=0.0001$ for gender and $F=4.32$, d.f. $=1,98$, and $P=0.04$ for density; Table 1). When considering outcrossed pollination events, only the density effects were significant $(F=6.11$, d.f. $=1,88$, and $P=0.015$ ). As expected, intermate distances of $<50 \mathrm{~m}$ were significantly more frequent among hermaphrodite mother trees $(Z=8.80, P<0.01)$ as a result of high frequency of selfing ( $d=0.0 \mathrm{~m}$, by definition) (Fig. 2). More interestingly, the cumulative frequency curve showed significant differences between gender types at distances beyond $250 \mathrm{~m}(Z=2.06$, $P=0.047$ ), with a higher frequency of long-distance pollination events for isolated female trees (Fig. 2). Density had a significant effect on female mother trees, and FL mother trees presented longer $d$ than FH mother trees. There were no observed

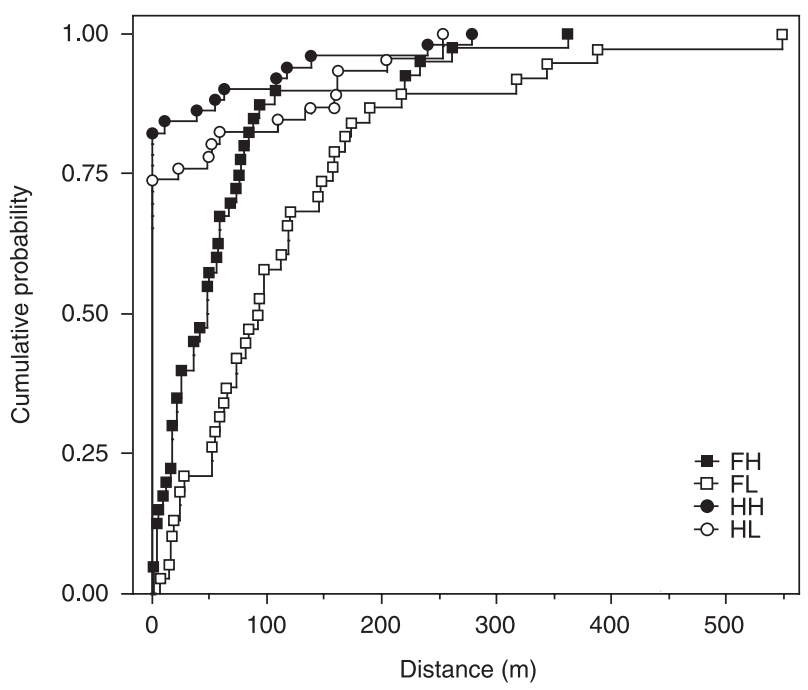

Fig. 2 Cumulative probability curves for the frequency distributions of intermate distances. Trees are grouped as female mother trees (squares) and hermaphrodite mother trees (circles), located in high density (solid) and low density (open) situations. A zero intermate distance represents self-pollination events.

differences between HL and HH in mean intermate distance when including or excluding selfing (Table 1).

\section{Canonical correlations of mating and ecological neighbourhood}

Variation in mating variables among individual trees was significantly related to differences in their ecological setting, as evidenced by the significant CCA (Wilk's $\lambda=0.0172, F=$ 2.657 , d.f. $=30,18$, and $P=0.042$ ). Only the first canonical variables (Mating1 and Ecol1) were significant, with a canonical correlation of $R^{2}=0.939(F=2.66, P=0.041)$; the best fit model with these two canonical variables explained $78.1 \%$ variation. The first mating canonical variable (Mating1) was negatively associated with outcrossing rate $\left(t_{m}\right)$ and increased relatedness among fathers $(r)$ (Table 2A). The ecological canonical variable, Ecol1, describes the growing site of the trees determined. This variable defines a gradient of increasing UCWC, mean UCHGT, higher number of UCSP, and higher UCOVR; the DFOREST was negatively correlated with this trend (Table 2A). Trees in dense clumps with high cover of other woody species and taller vegetation and are growing away from the pine forest edge had positive scores in this canonical variable. The mating variables which showed a more marked response to this ecological gradient were outcrossing rate $\left(t_{m}\right)$ and relatedness among siring trees $(r)$ (Table 2B). Outcrossing rate was negatively correlated with Ecol1, whereas $r$ was positively correlated with it (Table 2B). Thus, $t_{m}$ tends to decrease, and the $r$ among the fathers tends to increase when trees grow in dense patches of high vegetation cover, usually away form the pine forest edge. 
Table 2 Results of canonical correlations analysis involving mating variables and ecological measurements of trees and growing sites. Only the first canonical variable was significant. A, the canonical structure is described by the correlations between the original mating measurements and the canonical mating variable (Mating1); and by the correlation between the original and canonical ecological variables (Ecol1). B, correlations between the mating and the canonical ecological variables, Ecol1. Bold numbers $>0.40 ; P<0.05$, and d.f. $=18$

\begin{tabular}{lc}
\hline Original variable & Canonical variable \\
\hline A & \\
& Mating1 \\
$d$ & -0.0664 \\
$t_{m}$ & -0.4563 \\
$k$ & 0.1019 \\
$k_{e}$ & 0.1995 \\
$r$ & $\mathbf{0 . 4 6 5 1}$ \\
& Ecol1 \\
CNPY & 0.0362 \\
UCHGT & $\mathbf{0 . 4 6 1 7}$ \\
UCSP & $\mathbf{0 . 5 7 8 1}$ \\
UCWC & $\mathbf{0 . 5 2 8 3}$ \\
UCOVR & $\mathbf{0 . 4 9 2 7}$ \\
DFOREST & $-\mathbf{0 . 4 7 5 9}$ \\
B & \\
& \\
$d$ & $E c o l 1$ \\
$t_{m}$ & -0.0643 \\
$k$ & $-\mathbf{0 . 4 6 2 7}$ \\
$k_{e}$ & 0.0987 \\
$r$ & 0.1932 \\
\hline
\end{tabular}

\section{Discussion}

Despite the importance of pollen flow as a process shaping genetic structure in natural plant populations, little direct evidence of long distance events has been reported (Chase et al. 1996; White et al. 2002; Gaiotto et al. 2003). Previous work based on artificially arranged experimental plantations suggests that pollen dispersal patterns within and among populations are more complex than expected when only the distance component is considered (Richards et al. 1999). Our results with Prunus mahaleb confirm this by showing a marked influence not only of distance effects, but also of the complex landscape surrounding the reproductive trees. Evidence is given for low pollen immigration, with less than $10 \%$ of the seeds being sired by trees outside the population. While the area was exhaustively sampled, the presence of some isolated trees between our study population and the nearest one cannot however, be discounted. The amount of pollen immigration reported here is quantitatively low, but is substantial in terms of its potential implications, as it might represent consistent long-distance insect-mediated pollination events given that the nearest population is located at $1.5 \mathrm{~km}$. Our estimate is similar to previously reported direct estimates, ranging from one to several kilometres for Swietenia humilis (White et al. 2002), in one of the few studies focusing on a strictly isolated population. When geographical isolation involves differences in elevation and phenology, gene flow by pollen can be severely limited (Chase et al. 1996; Jordano \& Godoy 2000). The effect of phenology is illustrated in our data set by the fact that a single pollination event of the 200 embryos analysed came from a small group of trees $(N=17)$ located $300 \mathrm{~m}$ north of the main population site. These trees tend to flower earlier (P. Jordano, personal observation), which appears to limit pollen flow with the rest of the trees as a result of their largely non-overlapping phenologies. Distance alone cannot explain the low levels of pollen immigration in our study area, as insects may easily transport pollen over long distances (Janzen 1971; Chase et al. 1996; Nason et al. 1998; Fuchs et al. 2003). Chapman et al. (2003) documented that workers of Bombus terrestris and Bombus pascuorum colonies, both pollinators of $P$. mahaleb, travelled kilometres from their colonies. However, they are more likely to promote short distance pollen movement, particularly in high density and clumped situations such as our study site (Levin \& Kerster 1969; Harder 1990). Therefore, patchy regional distribution with populations separated over a kilometre, together with non-overlapping phenology because of altitudinal differences and a clumped arrangement of the adult trees, might favour locally restricted foraging of the pollinators and limit the number of long-distance pollination events.

Mating system variation was pervasively influenced by gender expression, as the variable for selfing levels was translated into significant differences in $t_{m}, k, k_{e}$, and $r$. The estimated values of outcrossing for hermaphrodite trees were slightly lower but congruent with the indirect estimate obtained previously, based on seed mass data and other values for self-compatible species (Jordano 1993 and references therein). Outcrossing rates were highly variable among hermaphrodites, as shown by their high standard deviation for HL and HH groups. Despite the potential limitations of the progeny sample, the data reveal robust differences. However, larger progeny arrays would be needed to assess variation at the tree level. The low outcrossing rates found in hermaphrodite trees (0.37-0.46) yielded low values of $k$ and $k_{e}$. We also found that fathers siring hermaphrodite trees were more related among themselves than fathers siring female trees. However, this cannot be attributed to selfing alone, as $r$ values were significantly higher when excluding selfing in hermaphrodites. Rather, variation between the two genders might be influenced by the local spatial genetic structure of the adult trees, as adults located within 35-m distance are genetically more similar than randomly expected (Jordano \& Godoy 2000). As female mother trees had a wider range of intermate distance, the relatedness among siring trees was lower than that of trees siring hermaphrodites. Thus, hermaphrodite mother trees received pollen from a lower 
number of fathers, contributing less evenly, and being more related among them than the fathers siring female trees. This effect appears as a direct consequence of the spacing patterns in the population. Previous studies have stated that, all else being equal, the larger the size of the paternity pool, the higher will be the fitness of the mother plant (Levin 1988). The combined effects of selfing biparental inbreeding and a less diverse pollen pool can explain the differences in fitness associated with gender type found by Jordano (1993) in the same studied population, where reduced fruit production and smaller seed mass were reported for hermaphrodite trees. From an evolutionary point of view, hermaphrodite trees disperse their genes twice (both at pollination and at seed dispersal stages), and because they do not depend on an external pollen source for successful fruit set, pollen limitation during unfavourable weather and low pollinator activity are less likely to occur (Jordano 1993 and references therein). Thus, a higher reproductive fitness of female trees can be invoked to explain their maintenance in the population. In our study area, almost $50 \%$ of the adult trees were female. These results, combined with previous analyses, indicate that the pollen cloud of female trees renders a highly diversified progeny that can result in a higher relative fitness, especially when pollinator activity is not limiting. However, additional field data relating variation in mating patterns to variation in fitness because of gender expression is needed to fully understand the evolution of the mixed-mating system and the persistence of the gynodioecious condition.

Gender type also influenced intermate distance, as selfing implies $d=0 \mathrm{~m}$ by definition. We thus found striking differences between gender types with respect to frequency of long distance pollination events, with female mother trees receiving pollen more frequently from hermaphrodites located at $250 \mathrm{~m}$ or further. This interesting result implies important differences between genders in the provenance of the pollen cloud beyond the obvious consequences of selfing. To our knowledge, differences in the distance of pollen dispersal between gender types have not been previously reported, although we do know that the species composition of the pollinator assemblage and visitation rates differed between female and hermaphrodites in the study population (Jordano 1993). Female flowers were significantly more visited than hermaphrodite flowers and their pollinator assemblage was dominated by calliphorid flies. On the other hand, hermaphrodite flowers were visited by solitary bees and syrphid flies (pollinivorous) in a similar proportion. Despite the dominance of calliphorid flies, female trees might be benefiting from the greater effectiveness of solitary bees in terms of pollen removal, flight distances, and visitation rates (see e.g. Herrera 1987). Reliable of solitary bees to female trees would assure pollen receipt from hermaphrodites even outside the denser patches.
The spatial arrangement and local density of the adult trees also shape pollen dispersal patterns. Handel (1983) found that, all other things being equal, a clumped arrangement of the trees favoured shorter intermate distances compared with more regular distributions. This is also illustrated in our study, as the observed intermate distance frequency distribution is more skewed and leptokurtic than expected from the potential intermate distances. Presumably pollinator foraging movements are enhancing pollen transfer among nearby trees, as was previously reported for entomophilous species where the pollen pool tended to be dominated by immediate neighbours when the trees grew in clumped patches (Broyles \& Wyatt 1991; Murawski \& Hamrick 1991; Stacy et al. 1996). Moreover, we found that isolated locations of the female mother trees (FL) tended to promote longer pollen dispersal distances, a more even contribution of the siring trees and a lower relatedness among them. Therefore, variations in mating system and pollen dispersal pattern due to gender expression and conspecific density might set a range of genetic variation among progenies: from highly selfed progeny of hermaphrodites $(\mathrm{HL}, \mathrm{HH})$ with a low number of siring trees (most of them highly correlated and located close to the mother tree) to the outcrossed progenies of females (FH and, especially, FL) with a high number of fathers contributing evenly and sometimes located far away from the mother tree. The importance of this variation might be related to environmental conditions during the pollination phase. A cold and stormy spring would decrease pollinator activity, yet fruits can be set from selfing, avoiding the collapse of the demographic cycle because of pollinator limitation. Sunny periods would favour pollinator activity and increase the outcrossed progeny and the contribution of isolated trees, thus increasing the effective number of trees at the population level. In this context, only a long-term study would elucidate the ecological and evolutionary consequences of variation in mixed-mating species by examining the interactions between weather conditions, pollinator activity, and mating patterns.

Not only the density of conspecifics, but also the ecological characteristics of the maternal neighbourhood determined mating pattern variation in our population. Thus, the canonical correlation analysis showed that dense maternal neighbourhoods (in terms of vegetation cover, and height and number of woody species) were associated with lower outcrossing rates and higher relatedness among the siring trees. The negative correlation of the mating canonical variable with the distance to the pine forest reflects the spatial distribution of the adult trees in the population, because open neighbourhoods with low vegetation cover tend to be located in the periphery of the population, near the pine forest edge (Fig. 1). Trees located in a more central position within the population, with a denser neighbourhood, tend to have progenies with lower $t_{m}$ and higher $r$ values. Most 
P. mahaleb pollinators are generalist, and a dense vegetation cover around a mother tree would enhance locally restricted foraging (Cresswell 1997), thus promote short intermate distances. Interestingly, our results show only a small influence of canopy size on the mating system, whereas previous works have emphasized the tree size/canopy size as an important factor influencing outcrossing rates (Burczyk et al. 1996; O'Connell et al. 2004). As we selected only adult trees, variation in the vertical projection of the canopy was small and consequently did not explain much variation in mating system. Individual variation in mating patterns is therefore the result of a complex interaction between gender expression, pollinator foraging, and the patchy environmental setting of complex landscapes.

Finally, consideration should be given to the dual role of functional female trees, both as targets for pollen receipt and as sources of dispersing seeds, especially in animaldispersed species. In fleshy-fruited species, mating variation of seed-bearing trees also influences the subsequent stages of seed dispersal, because the maternal tree acts as a source of dispersed seed. Our results indicate that outcrossed and less-related seeds tend to be produced by trees located closer to the pine forest edges, and that less diversified progeny is expected in dense patches. Additionally, we know that a fraction of variation in seed mass among trees is attributable to the breeding system, as outcrossed seeds are significantly heavier, and that frugivores show significant selection effects on fruits that will influence fruit removal success (Jordano 1993, 1995). Moreover, different frugivore species show marked differences in habitat preferences and tree visitation, and we expect a highly variable dispersal success of this heterogeneous progeny. Evidence from direct observation of frugivores indicates that isolated trees are more likely to benefit from long-distance dispersal by efficient frugivores compared to trees growing in dense patches (Jordano \& Schupp 2000; C. García \& $P$. Jordano, personal observation). These sequential effects illustrate the relevance of maternal trees as key demographical elements in plant populations, simply because gene flow patterns (via pollen and seeds) are pivotal on their individual effects. A thorough view of animal-mediated effects on total gene flow patterns would necessarily consider on one hand the combined influences of variation in mating patterns and in seed dispersal ecology, and on the other hand, the assessment of the male and female fitness functions and their ecological correlates. Our analysis shows that both pollen- and seed-related processes are linked through the mother tree, its ecological environment, and the complex landscape where pollinators and frugivores forage. The simultaneous use of progeny genotyping and spatially explicit analysis of environmental variables, including the outcomes of plant-animal interactions, will be key elements for an expanded approach to gene flow analysis considering dispersal via pollen and seeds.

\section{Acknowledgements}

We appreciate the help of P. Bazaga, Ch. Baier, M. Carrión, and S. Martín during all the stages of this project. The Consejería de Medio Ambiente (Junta de Andalucía) greatly facilitated our work in Parque Natural de las Sierras de Cazorla, Segura y Las Villas. Discussions with F. Austerlitz, S. Gerber, V. Orive, X. Picó, P. Smouse, V. Sork, A. Valido, and three anonymous referees, as well as suggestions by R. Petit, greatly improved earlier versions of the manuscript. Our work received the grants BOS2000-1366-C02-01 and REN2003-00273 from the Spanish Ministerio de Ciencia y Tecnología (MCyT) and RNM-305 (Junta de Andalucía). CG received a MCyT research grant (FP2000-5627).

\section{References}

Adams WT, Griffing AR, Moran GF (1992) Using paternity analysis to measure effective pollen dispersal in plant populations. American Naturalist, 140, 762-780.

Angers B, Magnan P, Plante M, Bernatchez L (1999) Canonical correspondence analysis for estimating spatial and environmental effects on microsatellites gene diversity in brook charr (Salvelinus fontinalis). Molecular Ecology, 8, 1043-1053.

Broyles SB, Wyatt R (1991) Effective pollen dispersal in a natural population of Asclepias exaltata: the influence of pollinator behaviour, genetic similarity, and mating success. American Naturalist, 138, 1239-1249.

Burczyk J, Adams WT, Shimizu JY (1996) Mating patterns and pollen dispersal in a natural knobcone pine (Pinus attenuata Lemmon.) stand. Heredity, 77, 251-260.

Chapman RE, Wang J, Bourke FG (2003) Genetic analysis of spatial foraging patterns and resources sharing in bumble bee pollinators. Molecular Ecology, 12, 2801-2808.

Charlesworth B, Chalesworth D (1978) A model for the evolution of dioecy and gynodioecy. American Naturalist, 112, 975-997.

Chase MR, Keseli R, Bawa K (1996) Distant gene flow in tropical trees. Nature, 383, 398-399.

Cresswell JE (1997) Spatial heterogeneity, pollinator behaviour and pollinator-mediated gene flow: bumblebee movements in variously aggregated rows of oil-seed rape. Oikos, 78, 546-556.

Devlin B, Ellstrand NC (1990) The development and application of a refined method for estimating gene flow from angiosperm paternity analysis. Evolution, 44, 248-259.

Devlin B, Roeder K, Ellstrand NC (1988) Fractional paternity assignment: theoretical development and comparison to other methods. Theoretical and Applied Genetics, 76, 369-380.

Ennos RA (2001) Inferences about spatial processes in plant populations from the analysis of molecular markers. In: Integrating Ecology and Evolution in a Spatial Context (eds Silvertown J, Antonovics J), pp. 45-71. Blackwell Science Ltd., London.

Everitt BS, Dunn G (1991) Applied Multivariate Data Analysis. Arnold Publisher, London.

Fuchs E, Lobo J, Quesada M (2003) Effects of forest fragmentation and flowering phenology on the reproductive success and mating patterns of the tropical dry forest tree Pachira quinata. Conservation Biology, 17, 149-157.

Gaiotto FA, Grattapaglia D, Vencovsky R (2003) Genetic structure, mating system, and long-distance gene flow in heart of palm (Euterpe edulis Mart.). Journal of Heredity, 94, 399-406.

Gerber S, Chabrier P, Kremer A (2003) FAMOz: a software for parentage analysis using dominant, codominant and uniparentally inherited markers. Molecular Ecology Notes, 3, 479-481. 
Gibson JP, Diggle P (1997) Structural analysis of female and hermaphroditic flowers of a gynodioecious tree, Ocotea tenera (Lauraceae). American Journal of Botany, 84, 298-307.

Godoy JA, Jordano P (2001) Seed dispersal: exact identification of source trees with endocarp DNA microsatellites. Molecular Ecology, 10, 2275-2283.

Godt MJ, Hamrick JL (1993) Patterns and levels of pollenmediated gene flow in Lathyrus latifolius. Evolution, 47, 98-110.

Gram W, Sork VL (2001) Association between environmental and genetic heterogeneity in forest tree populations. Ecology, 82, 2012-2021.

Handel SN (1983) Pollination ecology, plant population structure, and gene flow. In: Pollination Biology (ed. Real L), pp. 163-211. Academic Press, New York.

Harder LD (1990) Pollen removal by bumble bees and its implications for pollen dispersal. Ecology, 71, 1110-1125.

Hardy O, Vekemans X (2002) sPAGEDI: a versatile computer program to analyse spatial genetic structure at individual or population levels. Molecular Ecology Notes, 2, 618-620.

Herrera CM (1987) Components of pollinator 'quality': comparative analysis of a diverse insect assemblage. Oikos, 50, 79-90.

Janzen DH (1971) Euglossine bees as long-distance pollinators in tropical plants. Science, 171, 203-205.

Jordano P (1993) Pollination biology of Prunus mahaleb L. deferred consequences of gender variation for fecundity and seed size. Biological Journal of the Linnean Society, 50, 65-84.

Jordano P (1995) Frugivore-mediated selection on fruit and seed size: birds and St. Lucie's cherry, Prunus mahaleb. Ecology, 76, 2627-2639.

Jordano P, Godoy JA (2000) RAPD variation and population genetic structure in Prunus mahaleb (Rosaceae), an animaldispersed tree. Molecular Ecology, 9, 1293-1305.

Jordano P, Schupp E (2000) Seed disperser effectiveness: the quantity component and patterns of seed rain for Prunus mahaleb. Ecological Monographs, 70, 591-615.

Levin DA (1988) The paternity pool of plants. American Naturalist, 132, 309-317.

Levin DA, Kerster H (1969) Density-dependent gene dispersal in Liatris. American Naturalist, 103, 61-74.

Marshall TC, Slate J, Kruuk B, Pemberton JM (1998) Statistical confidence for likelihood-based paternity inference in natural populations. Molecular Ecology, 7, 639-655.

Meagher T (1986) Analysis of paternity within a natural population of Chamaelirium luteum. 1. Identification of most likely male parents. American Naturalist, 128, 199-215.

Mitchell A (1999) The ESRI Guide to GIS Analysis, Volume 1: Geographical Patterns and Relationships. ESRI Press, Redlands.

Murawski DA (1987) Floral resource variation, pollinator response, and pollen flow in Psiguria warscewiczii. Ecology, 68, 12731282.

Murawski DA, Hamrick JL (1991) The effect of the density of flowering individuals on the mating system of nine tropical tree species. Heredity, 67, 167-174.

Murawski DA, Hamrick JL (1992) The mating system of Cavanillesia platanifolia under extremes of flowering tree density: a test of predictions. Biotropica, 24, 99-101.
Nason JD, Herre EA, Hamrick JL (1998) The breeding structure of a tropical keystone plant resource. Nature, 39, 685-687.

Nielsen R, Tarpy DR, Reeve HK (2003) Estimating effective paternity number in social insects and the effective number of alleles in a population. Molecular Ecology, 12, 3157-3164.

O'Connell LM, Russell J, Ritland K (2004) Fine-scale estimation of outcrossing in western redcedar with microsatellite assay of bulked DNA. Heredity, 93, 443-449.

Queller DC, Goodnight KL (1989) Estimating relatedness using genetic markers. Evolution, 43, 258-275.

R Development Core Team (2003) R: a language and environment for statistical computing. R Foundation for Statistical Computing, Vienna, Austria.

Richards CM, Church S, McCauley DE (1999) The influence of population size and isolation on gene flow by pollen in Silene alba. Evolution, 53, 63-73.

Ritland K (1989) Correlated matings in the partial selfer Mimulus guttatus. Evolution, 43, 848-859.

Ritland K (2002) Extensions of models for the estimation of mating systems using $\mathrm{n}$ independent loci. Heredity, 88, 221-228.

SAS Institute (1998) SAS/STAT Users Guide. Release 6.03 edition. SAS Institute, North Carolina.

Schnabel A, Hamrick JL (1995) Understanding the population genetic structure of Gleditsia triacanthos (L.): the scale and pattern of pollen flow. Evolution, 49, 921-931.

Slate J, Marshall T, Pemberton J (2000) A restrospective assesment of the accuracy of the paternity inference program CERVUs. Molecular Ecology, 9, 801-808.

Smouse PE, Meagher TR, Kobak CJ (1999) Parentage analysis in Chamaelirium luteum (L.) Gray (Liliaceae): why do some males have higher reproductive contributions? Journal of Evolutionary Biology, 12, 1069-1077.

Smouse PE, Sork VL (2004) Measuring pollen flow in forest trees: an exposition of alternative approaches. Forest Ecology and Management, 197, 21-38.

Sork VL, Nason J, Campbell DR, Fernandez JF (1999) Landscape approaches to historical and contemporary gene flow in plants. Trends in Ecology \& Evolution, 14, 219-224.

Stacy EA, Hamrick JL, Nason JD, Hubbell SP, Foster RB, Condit R (1996) Pollen dispersal in low-density populations of three neotropical tree species. American Naturalist, 148, 275-298.

van Treuren R, Bijlsma R, Ouborg NJ, Van Delden W (1993) The effects of population size and plant density on outcrossing rates in locally endangered Salvia pratensis. Evolution, 47, 1094-1104.

Valle F, Gómez F, Mota F, Díaz C (1989) Parque Natural de Cazorla, Segura Y Las Villas; Guía Botánico-Ecológica. Editorial Rueda, Madrid.

Venables WN, Ripley BD (2002) Modern Applied Statistics with S. Springer-Verlag, New York.

Webb DA (1968) Prunus L. In: Flora Europaea (eds Tutin TG et al.). Cambridge University Press, Cambridge.

White GM, Boshier DH, Powell W (2002) Increased pollen flow counteracts fragmentation in a tropical dry forest: an example from Swietenia humilis Zuccarini. Proceedings of the National Academy of Sciences of the United States of America, 99, 2083-2042.

Zar JH (1999) Biostatistical Analysis. Prentice Hall International, New Jersey. 